\title{
A Low-Stress, Elastic, and Improved Hardness Hydrogenated Amorphous Carbon Film
}

\author{
Qi Wang, ${ }^{1}$ Deyan He, ${ }^{1}$ and Junyan Zhang ${ }^{2}$ \\ ${ }^{1}$ School of Physics, Lanzhou University, Lanzhou 730000, China \\ ${ }^{2}$ State Key Laboratory of Solid Lubrication, Lanzhou Institute of Chemical Physics, \\ Chinese Academy of Sciences, Lanzhou 730000, China \\ Correspondence should be addressed to Qi Wang; wangqi77@lzu.edu.cn
}

Received 6 October 2014; Accepted 2 December 2014

Academic Editor: Yuanlie Yu

Copyright (C) 2015 Qi Wang et al. This is an open access article distributed under the Creative Commons Attribution License, which permits unrestricted use, distribution, and reproduction in any medium, provided the original work is properly cited.

\begin{abstract}
The evolution of hydrogenated amorphous carbon films with fullerene-like microstructure was investigated with a different proportion of hydrogen supply in deposition. The results showed at hydrogen flow rate of $50 \mathrm{sccm}$, the deposited films showed a lower compressive stress (lower 48.6\%), higher elastic recovery (higher 19.6\%, near elastic recovery rate 90\%), and higher hardness (higher 7.4\%) compared with the films deposited without hydrogen introduction. Structural analysis showed that the films with relatively high $\mathrm{sp}^{2}$ content and low bonded hydrogen content possessed high hardness, elastic recovery rate, and low compressive stress. It was attributed to the curved graphite microstructure, which can form three-dimensional covalently bonded network.
\end{abstract}

\section{Introduction}

Hydrogenated amorphous carbon films with fullerene-like microstructure have attracted increasing attention due to their extraordinary properties of high mechanical hardness and low friction coefficient [1-4]. It can be as a protective coating in tooling components, such as knives, drill bits, dies, and molds, and as a coating on hard-disk platters and harddisk read heads. Until now, hydrogenated amorphous carbon films with fullerene-like microstructure had been synthesized by our group and other groups with different techniques including dc pulse plasma chemical vapor deposition (CVD), magnetron sputtering (MS), ECR CVD, and ICP CVD [1-8].

In this paper, hydrogenated carbon films were deposited with dc pulse plasma CVD system. The as-deposited carbon films could be considered as nanocomposite thin films with fullerene-like microstructure in the diamond-like carbon (DLC) matrix based on our previous results $[1,2]$. In order to study the evolution of structure and properties of films, a different content of $\mathrm{H}_{2}$ was introduced to the mixture of methane and hydrogen as feedstock. The deposition pressure was kept constant. The result discloses the close relationship between $\mathrm{sp}^{2}$ content, bonded hydrogen content and hardness, elastic recovery rate, and compressive stress. The film deposited at hydrogen flow rate 20 and $50 \mathrm{sccm}$ showed higher hardness and elastic and lower compressive stress.

\section{Experiments}

Hydrogenated amorphous carbon films were prepared on $\mathrm{Si}$ (100) substrates at different flux ratio of methane to hydrogen in the mixture which was about $1: 0,1: 1,1: 2,1: 5$, and $1: 10$ by dc-pulse plasma CVD technique. The flux of methane was kept constantly at $10.3 \mathrm{sccm}$. The deposition pressure was kept at $13 \mathrm{~Pa}$. After deposition, optical profilometry, Xray photoelectron spectra (XPS), reflection Fourier transform infrared (FTIR) spectra, and high-resolution transmission electron microscopy (HRTEM) were applied to probe the microstructure. Nanoindentation was applied to assess mechanical properties of the films.

\section{Results and Discussion}

Figure 1(a) shows the thickness and compressive stress of hydrogenated amorphous carbon films deposited with $\mathrm{dc}$ pulse plasma CVD versus $\mathrm{H}_{2}$ flow rate. The film thickness 


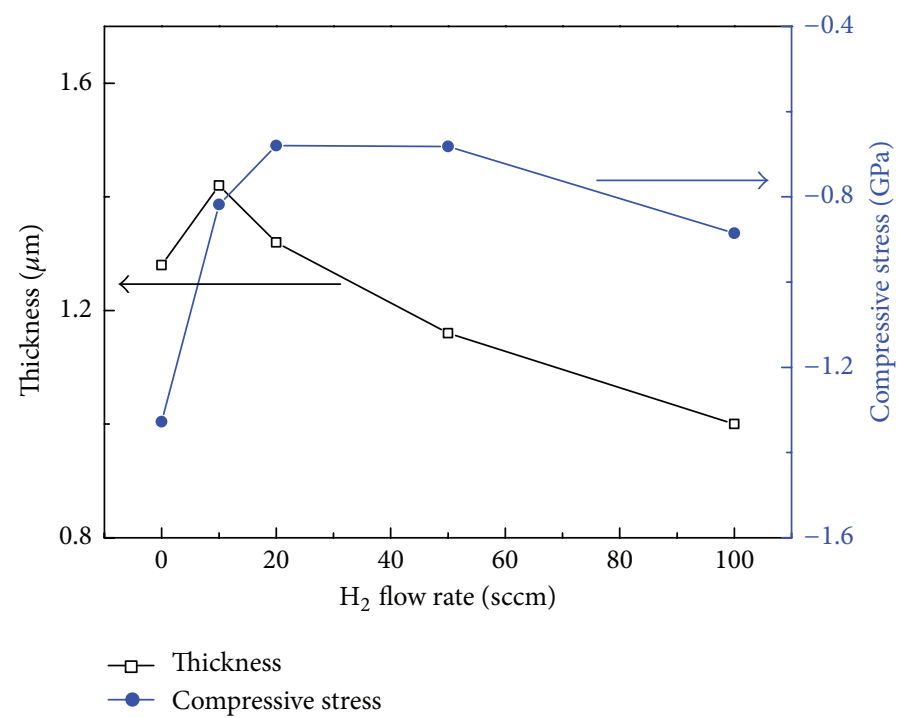

(a)

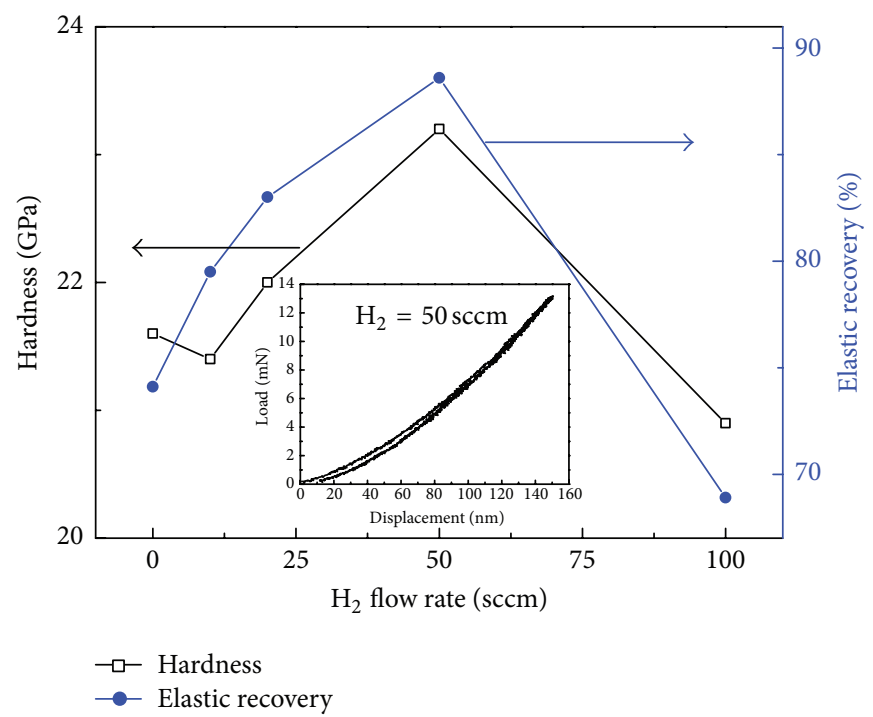

(b)

Figure 1: (a) Thickness and compressive stress of the as-deposited hydrogenated amorphous carbon films versus $\mathrm{H}_{2}$ flow rate; (b) hardness and elastic recovery $R$ of the as-deposited hydrogenated amorphous carbon films versus $\mathrm{H}_{2}$ flow rate.

values were measured by surface profilometer. The compressive stress values were calculated by Stoney's equation with curvature radii that were measured by optical profilometry. It is obvious that the compressive stress value decreased quickly when $\mathrm{H}_{2}$ was introduced into the mixture gas as feedstock. The values for the films deposited at $\mathrm{H}_{2} 20$ and $50 \mathrm{sccm}$ are lower $(\sim 48.6 \%)$ than the film deposited without $\mathrm{H}_{2}$ introduction. Generally, for amorphous carbon films, the decrease of compressive stress is corresponding to the structure transform of $\mathrm{sp}^{3}$-bonded atoms to $\mathrm{sp}^{2}$-bonded atoms.

Figure 1(b) exhibited the mechanical properties of the hydrogenated amorphous carbon films versus the $\mathrm{H}_{2}$ flow rate. In our experiment, in order to minimise the effect of substrate, the maximum indentation depth was kept at 1/7 of the film thickness. Five replicate indentations were made for each film sample. The elastic recovery $R$ was defined as $R=\left(d_{\max }-d_{\text {res }}\right) / d_{\max }$, where $d_{\max }$ and $d_{\text {res }}$ were the maximum displacement at the maximum load and the residual displacement after unloading, respectively [9]. This is a clear indication of plastic deformation regime. For the films deposited using dc-pulse plasma CVD versus the $\mathrm{H}_{2}$ flow rate, the mechanical properties increased at the beginning, as shown in Figure 1(b). When the $\mathrm{H}_{2}$ flow rate increased to $50 \mathrm{sccm}$, the hardness of the film was as high as $\sim 23.2 \mathrm{GPa}$, $7.4 \%$ higher compared to $\sim 21.6 \mathrm{GPa}$ for the film deposited without $\mathrm{H}_{2}$ introduction, and the elastic recovery $R$ was as high as $\sim 88.6 \%, 19.6 \%$ higher compared to $\sim 74.1 \%$ for the film deposited without $\mathrm{H}_{2}$ introduction. When the $\mathrm{H}_{2}$ flow rate increased to $100 \mathrm{sccm}$, there was a sharp decrease for hardness and elastic recovery. The values were decreased to $\sim 20.9 \mathrm{GPa}$ 


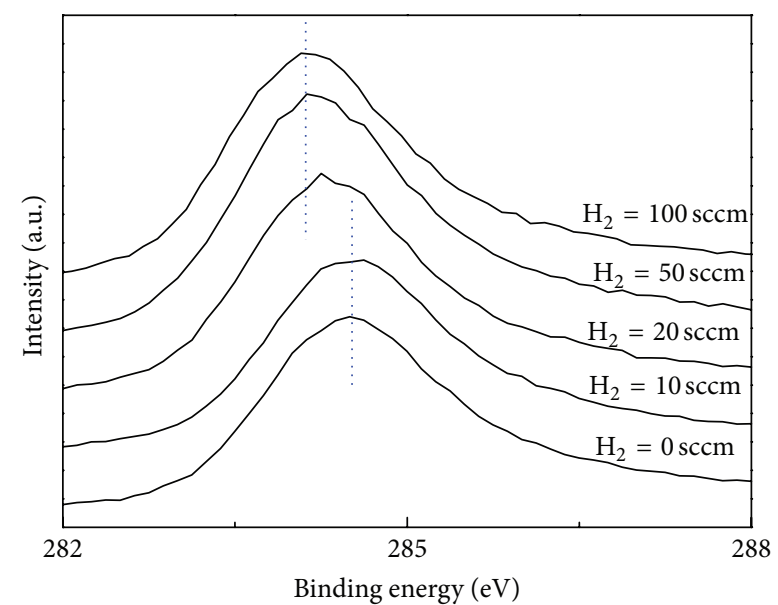

FIGURE 2: XPS spectra of as-deposited hydrogenated amorphous carbon films versus $\mathrm{H}_{2}$ flow rate.

and $\sim 68.9 \%$, respectively. In order to reveal the reason of the transform and the origin of lower stress, higher hardness, and elastic recovery $R$, it is necessary to perform the films' structure probing to reveal the structure factor.

Figure 2 shows the C1s core level XPS spectra of hydrogenated amorphous carbon films versus different $\mathrm{H}_{2}$ flow rates. In this paper, Au thin film about $0.2 \mathrm{~nm}$ was deposited on the test surfaces so as to minimize the charging effect in the XPS analysis. The C1s peak can be decomposed into two peaks: $\mathrm{sp}^{2}$ and $\mathrm{sp}^{3}$. The one around $284.3 \mathrm{eV}$ corresponded to $\mathrm{sp}^{2}$ carbon atoms, and that around $285.2 \mathrm{eV}$ corresponded to $\mathrm{sp}^{3}$ carbon atoms [10]. The Cls binding energy position of the film deposited without $\mathrm{H}_{2}$ introduction is $\sim 284.6 \mathrm{eV}$. As the $\mathrm{H}_{2}$ flow rate increased, except at the $\mathrm{H}_{2}$ flow rate of $10 \mathrm{sccm}$, a clear chemical shift to lower binding energy showed at $\mathrm{H}_{2}$ flow rate of 20,50 , and $100 \mathrm{sccm}$. We concluded that the $\mathrm{sp}^{2}$ carbon structure increased with the increased $\mathrm{H}_{2}$ flow rate. It was likely that excess $\mathrm{H}_{2}$ flow rate increased the impact of ion etching and impingement and led to the structure transformation from $\mathrm{sp}^{3}$ to $\mathrm{sp}^{2}$. In particular, the binding energy positions of $\mathrm{Cls}$ at the $\mathrm{H}_{2}$ flow rate of 50 and $100 \mathrm{sccm}$ are very close to the binding energy of $\mathrm{Cls}$ for pure graphite, $284.3 \mathrm{eV}$ [11]. Combined with the data of stress, hardness, and elastic recovery $R$, the reason for the improved properties of the film deposited at $\mathrm{H}_{2}$ flow rate of 20 and $50 \mathrm{sccm}$ should be the increased $\mathrm{sp}^{2}$ structure. It mainly existed in the form of fullerene-like curved graphite structure. The increased binding energy level at $\mathrm{H}_{2}$ flow rate of $10 \mathrm{sccm}$ is due to the defects (dangling bonds) in the films that were ended or occupied by $\mathrm{H}$ atoms when $\mathrm{H}_{2}$ was introduced, which prompted the formation of $\mathrm{sp}^{3}$ structure.

In order to get a better understanding of the bonding structure of all the samples, reflection FTIR spectra were invoked to determine the $\mathrm{C}-\mathrm{H}$ bonding configuration. The bonded hydrogen content in films can be applied as a probe to detect the structural environment of the attached carbon atoms due to the localized nature of the $\mathrm{C}-\mathrm{H}$ vibration. FTIR spectrum was widely used in this sense to characterize the

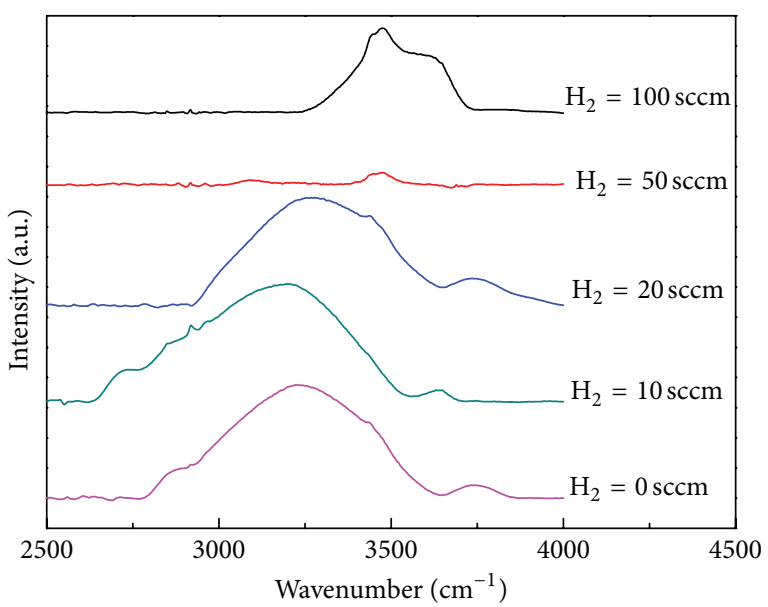

FIGURE 3: Reflection IR spectra of as-deposited hydrogenated amorphous carbon films versus $\mathrm{H}_{2}$ flow rate.

$\mathrm{C}-\mathrm{H}$ bonding in hydrogenated carbon films. It is known that the FTIR intensity of amorphous carbon films is relevant to the hydrogen incorporation.

Generally, the peaks in the range of $2800-3300 \mathrm{~cm}^{-1}$ are attributed to the different stretching vibrations of $\mathrm{C}$ $\mathrm{H}$ bonds. The $\mathrm{C}-\mathrm{H}$ stretching modes can break down into three regions, the $\mathrm{sp}^{1} \equiv \mathrm{C}-\mathrm{H}$ modes centre on $3300 \mathrm{~cm}^{-1}$, the $\mathrm{sp}^{2}=\mathrm{CH}_{n}$ modes lie from 2975 to $3085 \mathrm{~cm}^{-1}$, and $\mathrm{sp}^{3}-\mathrm{C}-$ $\mathrm{H}_{n}$ modes lie from 2850 to $2955 \mathrm{~cm}^{-1}$ [12]. Figure 3 shows the reflection FTIR spectra of as-deposited hydrogenated amorphous carbon films versus the $\mathrm{H}_{2}$ flow rate. For the film deposited without $\mathrm{H}_{2}$ introduction, the peak was broad, and it can conclude $\mathrm{sp}^{3}-\mathrm{C}-\mathrm{H}_{n}, \mathrm{sp}^{2}=\mathrm{CH}_{n}$, and $\mathrm{sp}^{1} \equiv \mathrm{C}-$ $\mathrm{H}$ complexes. However, by carefully examining the peaks, it is also found that there is a clear chemical shift to high wavenumber at $\mathrm{H}_{2}$ flow rate of 20,50, and $100 \mathrm{sccm}$, and the peak intensity at the flow rate of $50 \mathrm{sccm}$ decreased sharply, indicating a reduction of bonded hydrogen in carbon films. At the $\mathrm{H}_{2}$ flow rate of $10 \mathrm{sccm}$, since the defects (dangling bonds) in the films probably could be ended or occupied completely by $\mathrm{H}$ ions generated by methane and $\mathrm{H}_{2}$, which prompt the formation of $\mathrm{sp}^{3}$ structure, the peak position has a little shift to lower wavenumber. The analysis of increased $\mathrm{sp}^{3}$ content is consistent with that provided by XPS. When $\mathrm{H}_{2}$ content further increased, impact of ion etching and impingement increased, and $\mathrm{sp}^{3}-\mathrm{C}-\mathrm{H}_{n}$ changed into $\mathrm{sp}^{2}$ $=\mathrm{CH}_{n}$ and $\mathrm{sp}^{1} \equiv \mathrm{C}-\mathrm{H}$. As the $\mathrm{H}_{2}$ flow rate was increased to $50 \mathrm{sccm}$, mounts of $\mathrm{C}-\mathrm{H}$ bonding were destroyed; $-\mathrm{H}$ easily combined each other to form $\mathrm{H}_{2}$ and led to a loss of hydrogen content in the as-deposited film. It is obvious that the structure was gradually turned into $\mathrm{sp}^{2}$. When $\mathrm{H}_{2}$ flow rate increased further, impact of ion etching and impingement was strong and led to porous structure in film. We suggest that this is the reason for the absorption peak of $\mathrm{H}_{2} \mathrm{O}$ at a wavenumber of $3400-3700 \mathrm{~cm}^{-1}$ for the film deposited at $\mathrm{H}_{2}$ flow rate of $100 \mathrm{sccm}$. Combined with XPS spectra, the reason of the improved properties of the film deposited at $\mathrm{H}_{2}$ flow rate of 20 and $50 \mathrm{sccm}$ should be the 


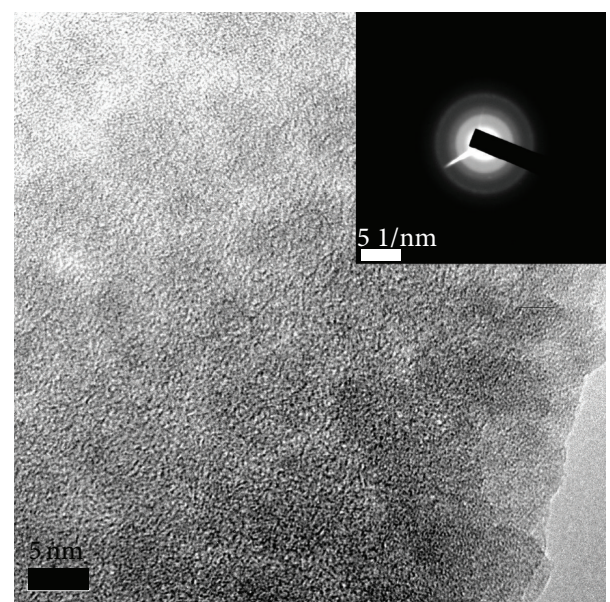

Figure 4: TEM images of as-deposited hydrogenated amorphous carbon films versus $\mathrm{H}_{2}$ flow rate of $50 \mathrm{sccm}$. The scale bar represents $5 \mathrm{~nm}$.

increased $\mathrm{sp}^{2}$ structure that mainly existed in the form of fullerene-like curved graphite structure, and the reason for poor properties of the film deposited at $\mathrm{H}_{2}$ flow rate of $100 \mathrm{sccm}$ should be the porous structure of the film formed in deposition process.

Figure 4 shows the HRTEM image of the hydrogenated amorphous carbon film deposited at $\mathrm{H}_{2}$ flow rate of $50 \mathrm{sccm}$ by dc pulse plasma CVD, displaying amorphous structure. There is no obvious ordered fullerene-like curved graphite structure. The corresponding SAED pattern indicates the amorphous structure of the film and displays three corresponding measures of spacing of $1.15,2.00$, and $3.50 \AA$. The two rings at 1.15 and $2.00 \AA$ coincide with those observed for amorphous carbon structure, whereas the ring at $3.50 \AA$ matches well the interplane spacing of hexagonal basal planes of graphite (0002) [13]. The appearance of a broad feature at $3.50 \AA$ indicates the presence of defective graphitic planes and confirms the formation of fullerene-like structure in as-deposited films. However, the fullerene-like features in our HRTEM image are not so clear compared to the other reports $[2,14]$. The reason is mainly from the too large thickness for HRTEM samples. Meanwhile, the HRTEM image can be seen from our previous reports. Combined with XPS and FTIR spectra results, it was reasonably concluded that the improved mechanical properties were corresponding to increased curved graphite (fullerene-like) structure. We speculated the reason why there was no obvious curved graphite structure that was from the impact of ion etching and impingement and led to a poor order of the structure.

It was obvious that the improvement of mechanical property versus $\mathrm{H}_{2}$ flow rate was due to the change of microstructure. It was much different from conventional hydrogenated amorphous carbon films, in which the mechanical properties decreased as $\mathrm{sp}^{2}$ bonding structure increased; in other words, a high concentration of $\mathrm{sp}^{2}$ graphitic bonds indicates soft film. Recently, the nanostructure of the films may also play dominant role in determining the mechanical properties of amorphous carbon films $[1,2]$. This thought is supported by the recent report that the mechanical properties of DLC films probably are not only dominated by $\mathrm{sp}^{3}$ fraction but also the degree of the $\mathrm{sp}^{2}$ bonding arrangement. In this paper, combined with XPS results, according to our and other researchers' reports, fullerene-like microstructure in the hydrogenated carbon matrix could be considered as the structure factor for the lower compressive stress, high hardness, and high elasticity. The film can possess lower stress, higher hardness, and higher elasticity by adjusting $\mathrm{sp}^{2}$ content and bonded hydrogen content.

\section{Conclusion}

In summary, the evolution of structure and mechanical properties of the hydrogenated amorphous carbon films with fullerene-like microstructure was investigated. The results showed that at hydrogen flow rate of $50 \mathrm{sccm}$, the deposited hydrogenated amorphous carbon films exhibited lower compressive stress (lower 48.6\%), higher elastic recovery (higher $19.6 \%$, near elastic recovery rate $90 \%$ ), and higher hardness (higher 7.4\%) compared with the films deposited without hydrogen introduction. Structural analysis showed that the film with relatively high $\mathrm{sp}^{2}$ content and low bonded hydrogen content possessed high hardness, elastic recovery rate, and low compressive stress. It was attributed to the curved grapheme microstructure, which can form threedimensional covalently bonded network. Meanwhile, when excess $\mathrm{H}_{2}$ was introduced, impact of ion etching and impingement was strong and led to porous structure in film.

\section{Conflict of Interests}

The authors declare that there is no conflict of interests regarding the publication of this paper.

\section{Acknowledgment}

The project was financially supported by the Ph.D. Programs Foundation of Ministry of Education of China with Grant no. 20100211120017.

\section{References}

[1] Q. Wang, C. B. Wang, Z. Wang, J. Y. Zhang, and D. He, "Fullerene nanostructure-induced excellent mechanical properties in hydrogenated amorphous carbon," Applied Physics Letters, vol. 91, no. 14, Article ID 141902, 2007.

[2] C. B. Wang, S. R. Yang, Q. Wang, Z. Wang, and J. Y. Zhang, "Super-low friction and super-elastic hydrogenated carbon films originated from a unique fullerene-like nanostructure," Nanotechnology, vol. 19, no. 22, Article ID 225709, 2008.

[3] Z. Wang and J. Zhang, "Deposition of hard elastic hydrogenated fullerenelike carbon films," Journal of Applied Physics, vol. 109, no. 10, Article ID 103303, 4 pages, 2011.

[4] J. G. Buijnsters, M. Camero, R. Gago, A. R. Landa-Canovas, C. Gómez-Aleixandre, and I. Jiménez, "Direct spectroscopic evidence of self-formed C60 inclusions in fullerenelike hydrogenated carbon films," Applied Physics Letters, vol. 92, no. 14, Article ID 141920, 2008. 
[5] J. G. Buijnsters, R. Gago, I. Jiménez, M. Camero, F. AgullóRueda, and C. Gómez-Aleixandre, "Hydrogen quantification in hydrogenated amorphous carbon films by infrared, Raman, and x-ray absorption near edge spectroscopies," Journal of Applied Physics, vol. 105, no. 9, Article ID 093510, 2009.

[6] P. Wang, X. Wang, B. Zhang, and W. M. Liu, "Structural, mechanical and tribological behavior of fullerene-like carbon film," Thin Solid Films, vol. 518, no. 21, pp. 5938-5943, 2010.

[7] L. Ji, H. Li, F. Zhao, W. L. Quan, J. M. Chen, and H. D. Zhou, "Effects of pulse bias duty cycle on fullerenelike nanostructure and mechanical properties of hydrogenated carbon films prepared by plasma enhanced chemical vapor deposition method," Journal of Applied Physics, vol. 105, no. 10, Article ID 106113, 2009.

[8] J. Robertson, "Diamond-like amorphous carbon," Materials Science \& Engineering: R: Reports, vol. 37, no. 4-6, pp. 129-281, 2002.

[9] M. A. Tamor and W. C. Vassell, "Raman 'fingerprinting' of amorphous carbon films," Journal of Applied Physics, vol. 76, no. 6, pp. 3823-3830, 1994.

[10] F. Tuinstra and J. L. Koenig, "Raman spectrum of graphite," Journal of Chemical Physics, vol. 53, no. 3, pp. 1126-1130, 1970.

[11] G. Abrasonis, R. Gago, M. Vinnichenko, U. Kreissig, A. Kolitsch, and W. Möller, "Sixfold ring clustering in $s p^{2}$ dominated carbon and carbon nitride thin films: a Raman spectroscopy study," Physical Review B, vol. 73, no. 12, Article ID 125427, 2006.

[12] A. C. Ferrari and J. Robertson, "Interpretation of Raman spectra of disordered and amorphous carbon," Physical Review BCondensed Matter and Materials Physics, vol. 61, no. 20, pp. 14095-14107, 2000.

[13] J. Díaz, G. Paolicelli, S. Ferrer, and F. Comin, "Separation of the $s p^{3}$ and $s p^{2}$ components in the C1s photoemission spectra of amorphous carbon films," Physical Review B: Condensed Matter and Materials Physics, vol. 54, no. 11, pp. 8064-8069, 1996.

[14] W. T. Zheng, H. Sjöström, I. Ivanov et al., "Reactive magnetron sputter deposited $\mathrm{CN}_{x}$ : effects of $\mathrm{N}_{2}$ pressure and growth temperature on film composition, bonding, and microstructure," Journal of Vacuum Science \& Technology A: Vacuum, Surfaces and Films, vol. 14, no. 5, pp. 2696-2701, 1996. 

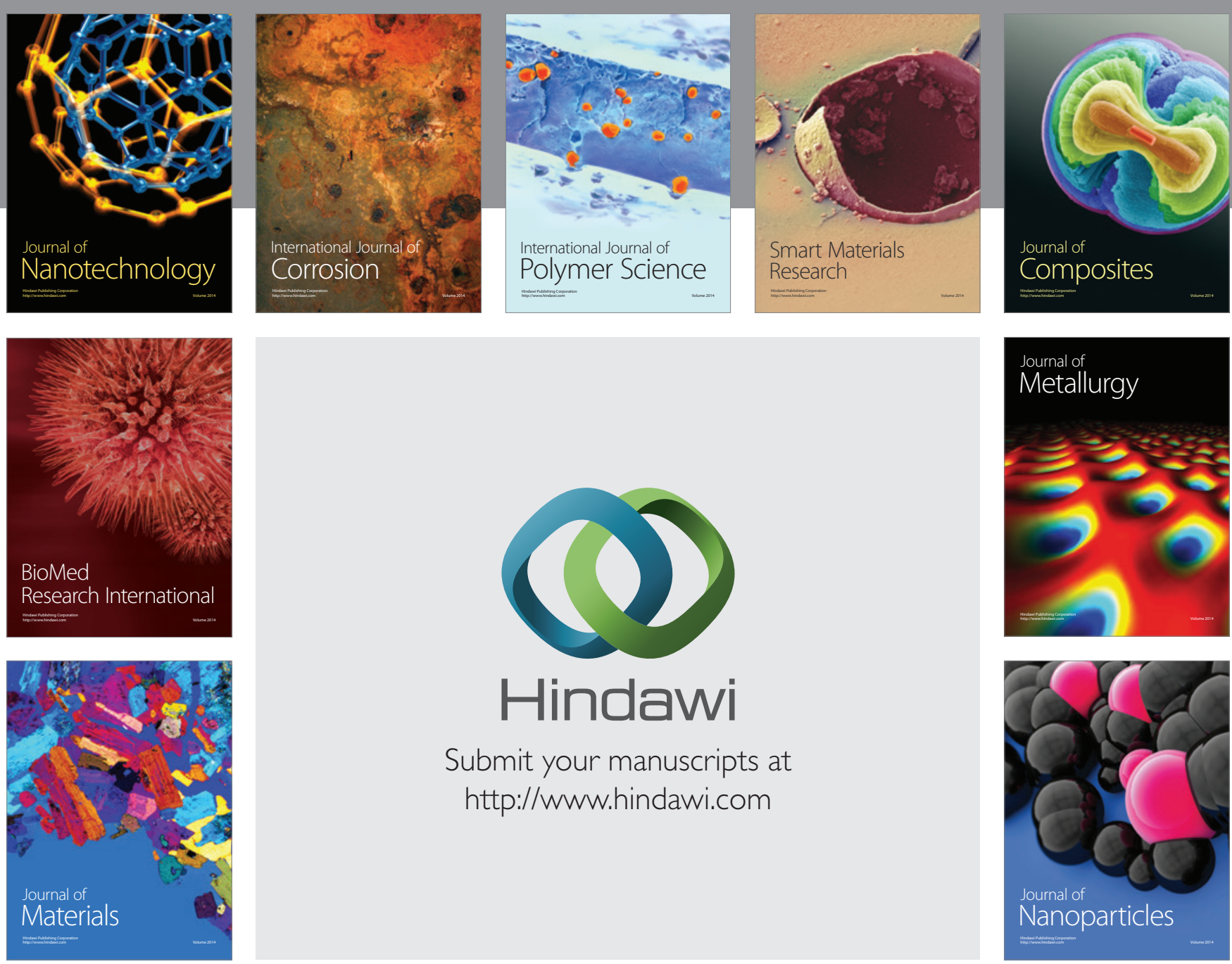

Submit your manuscripts at http://www.hindawi.com
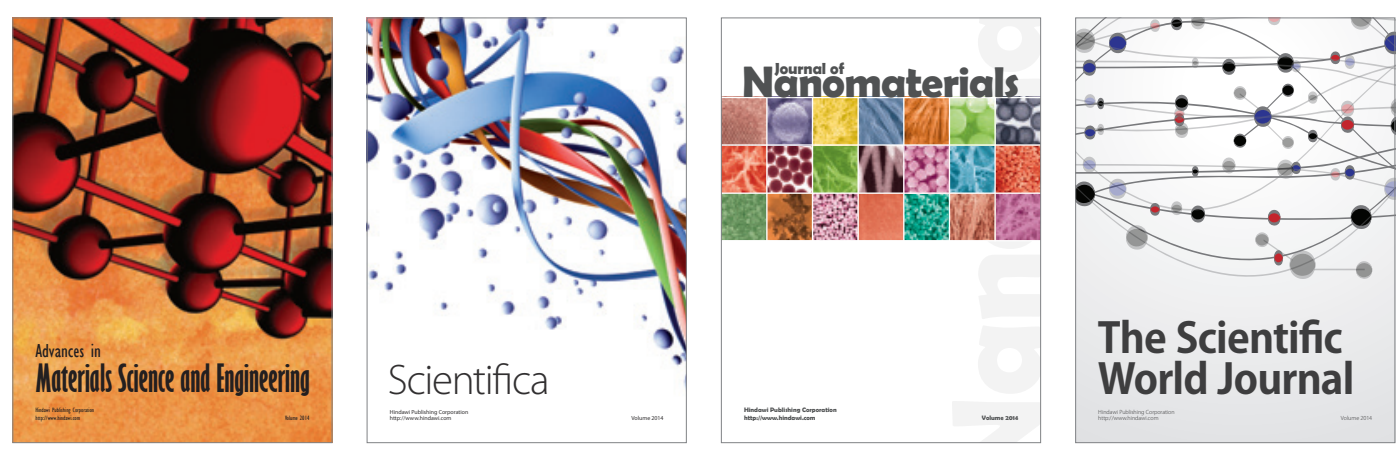

\section{The Scientific World Journal}
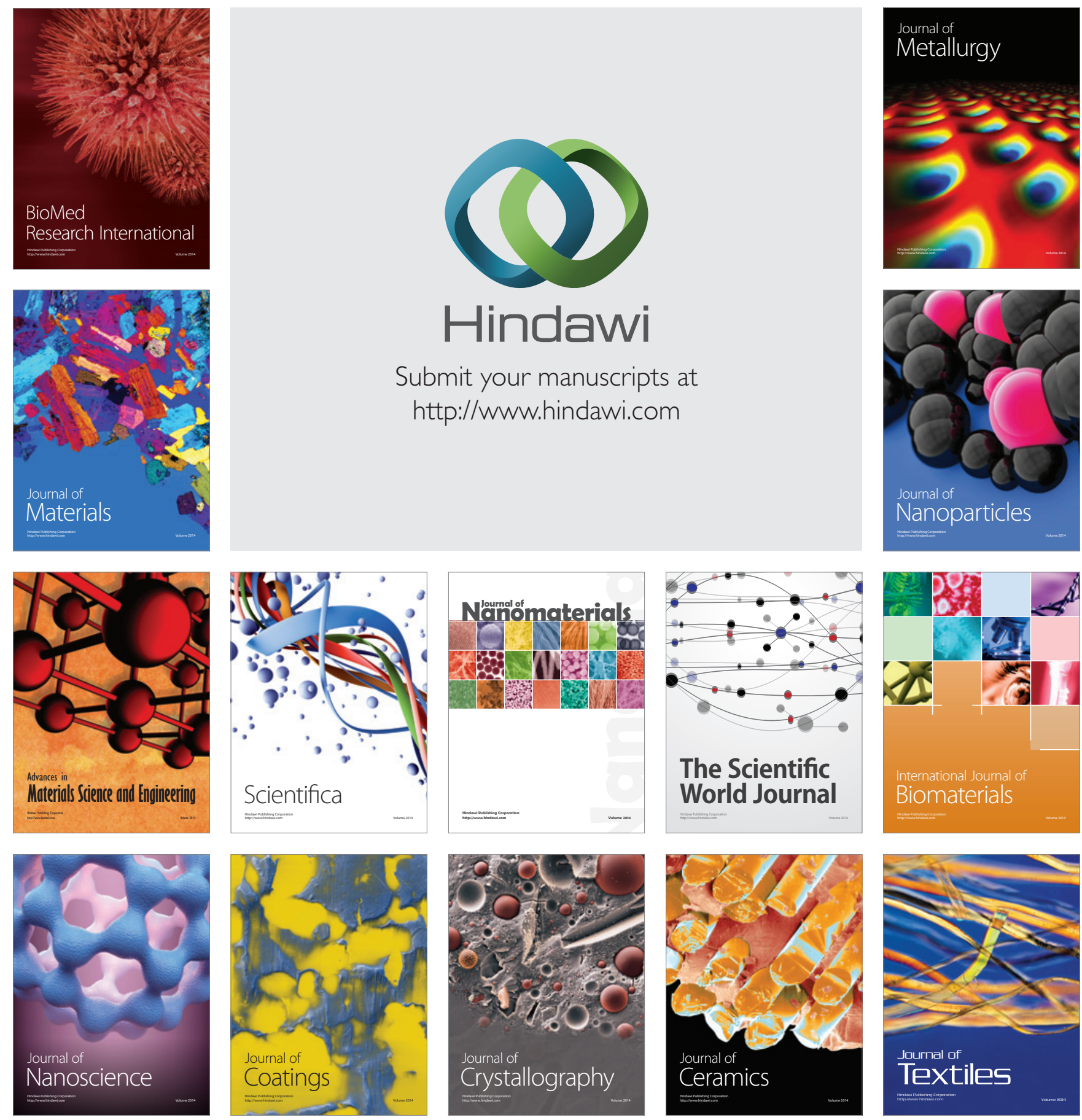